\title{
EVALUATION OF INVESTMENT PROJECT FOR BIOMASS USAGE WITH RISK CONSIDERATION
}

Jozef REPISKÝ, Department of Statistics and Operational Research, Faculty of Economics and Management, Slovak University of Agriculture in Nitra, jozef.repisky@uniag.sk (corresponding author)

Mária GRÁCOVÁ, Department of Statistics and Operational Research, Faculty of Economics and Management, Slovak University of Agriculture in Nitra, maria.gracova@gmail.com

\begin{abstract}
The paper is focused on a creation and evaluation of the investment project of pelletisation line purchase with a risk taken into consideration via a simulation model. The decision making subject was offered a choice of two pelletisation lines differentiating in technical parameters and purchase costs. The fundament of this work was a creation of a multi period balance model and formation of ten variants of the individual projects which differ in production volume and mean of financing. The main evaluation criterion of the deterministic calculations was a net present value which takes into consideration the time factor and belongs among the dynamic methods. By means of sensitivity and simulation analysis is possible to identify an appropriate investment strategy under the risk conditions. The risk factors, which were identified by sensitivity analysis, are defined as random variables with certain probability distribution. Critical values of target criterion give information value which we can expect with willingness to tolerate given risk quantification. The comparison of distribution functions of investment alternatives allows the identification of the optimal strategy. On the basis of the gained results we came to the conclusion that the purchase of the pelletisation line is a profitable investment which can increase the value of the company itself.
\end{abstract}

Keywords: biomass, investment, multiperiodical balance model, net present value, pelletisation line, risk evaluation, simulation model.

\section{INTRODUCTION}

The ecology and the environment preservation are connected with trends of using the renewable sources of energy, among which belongs the biomass. The geographic location of the Slovak Republic is predestined to offer a comparative advantage in the area of biomass sources. The biggest producer of the biomass in Slovakia is the agriculture and forest industry. The area of the agricultural land covers $47 \%$ of Slovakia and of the forest land is $41 \%$. The complete potential of the biomass in Slovakia is given as $40453 \mathrm{TJ} / \mathrm{year}(11237 \mathrm{GWh} /$ year), what makes the biomass to represent the highest ratio (35\%) of the complete potential of the renewable sources in Slovakia (Fáber, 2012).

The biomass is possible to process in many different ways, including an agropellet production. One of the supporting ideas for the formation and evaluation efficiency of the investment intention is a purchase of the production line which serves for the agropellet production and subsequent risk consideration can be the model technique application either.

\section{AIM AND METHODOLOGY}

The aim of this paper is evaluation of the investment project to purchase the production line for agropellet production via the model technique. The model solution is realized in a table processor Excel which enables a deterministic assessment of the investment project with resultant risk evaluation of the investment intention. For the economic efficiency evaluation and risk variants were created two types of models:

Multiperiodical balance model of the investment project - it enables the realization of the deterministic evaluation of the efficiency on the basis of the net present value criterion (Northcott, 1992; Lumby, 1996; Repiský, 2000).

$$
\mathrm{NPV}=\sum_{\mathrm{t}=1}^{\mathrm{n}} C F_{t} \frac{1}{(1+i)^{t}}-I_{\mathrm{o}}
$$

where: NPV net present value

Copyright (C) 2015 The Authors. Published by Aleksandras Stulginskis University. This is an open-access article distributed under the terms of the Creative Commons Attribution License (CC-BY 4.0), which permits unrestricted use, distribution, and reproduction in any medium, provided the original author and source are credited. 


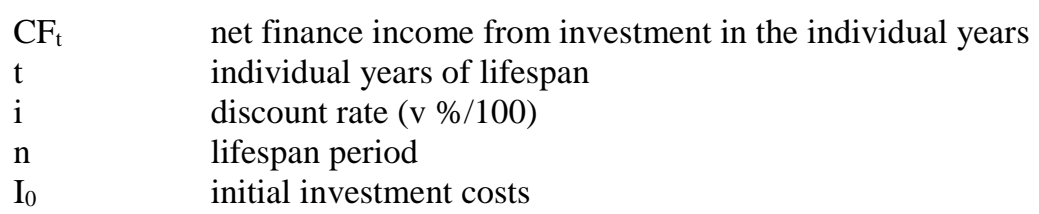

Sum of the financial costs during the lifespan of the investment has to ensure the covering of the expended financial sources, required revenue rate presented in the discount rate and should increase the cash flow what would raise the market value. The condition will be reached by the enterprise if the value of the net present value is positive.

Simulation model - by means of which was evaluated the risk of the individual investment intentions (Sojková, 2000; Repiský, 2000; Repiský, 2006). The simulation analysis as follows:

1. Creation of the investment project variants

2. Own analysis which lies in the subsequent phases:

- Identification of the input variables, influencing the target criterion indicators,

- Construction of the model for the criterion indicator calculation,

- Risk factor specification,

- Estimation of the shape of risk factors distribution and the estimation of distribution parameters,

- Construction of the probability distribution of the analysed criterion indicator and determination of its basic characteristics.

Results from the two first phases of the own risk analysis are known from the deterministic model. The sensitivity analysis was used to conduct the third phase. On its ground were identified as risk factors the variables the change of which result in a significant change of the final criterion indicator. It means that the risk factor is for instance the random variable, which $10 \%$ change causes more than $10 \%$ change of the observed criterion. In the fourth phase were for the distribution type estimates used subjective estimates based on experts'statements.

The information necessary for the realisation of the project were acquired from the real data of companies doing business in the area, professional literature and web page of a company dealing with pelletisation lines distribution. Flexibility of the model ensures a simple adjustment of the changing input values of the individual variables and thus gaining of the current and credible outcomes.

\section{RESULTS AND DISCUSSION}

\section{Technological lines for pellet production}

A suitable way of the biomass remains processing is production of agropellets. The agropellets are made by compaction of dry crushed parts of plants using press machines without any binding agent. They are in a form of mini briquettes of a cylindrical shape. Heating value of the agropellets does not change while production (pressing), it is the same as the heating value of the material they are made of. A content of ash is various regarding the agropellet type, however, it is the same as the content of ash of the straw as an original material, while it is lower than in brown or black coal. The ash from the biomass is an excellent phosphate-potassium fertilizer.

The main advantage of the pellets is a possibility of automation of the burning process in small and medium sized energetic boilers. The pellets of agro-material can be used as mulch. The agropellets can be utilized as bedding for animals. The distributor of the pelletisation lines offers technologies for production of pellets from the agricultural phytomass (grain straw, rape straw, corn haulm, waste) with various production and economic parameters. The offer includes transport costs and line assembly on a site of a future plant.

The given durability of the machine is in the length of 6 years. Based on real experience the line can serve its purpose even longer time period than is the given lifespan, in our case is minimal period of 12 years during which we observe the return of the investment. The special lines for the pellet production consist of the following: electric control, entrance conveyor for straw bales, sorter and crusher of straw bales, pneumatic transport of the crushed straw, filter, crushed straw container, humidifier, granulator, pellet conveyor, cooler and sorter.

We consider two types of lines in the contribution. The installed performance of the A line is $227 \mathrm{kWh}, \mathrm{B}$ line is $525 \mathrm{kWh}$. The average performance if the A line is $1 \mathrm{t} / \mathrm{h}, \mathrm{B}$ line $3 \mathrm{t} / \mathrm{h}$. The investment costs for the A line are $315165 €$ and B line $661320 €$. The costs for a building and transformer for A line are $50000 €$, for the B line $70000 €$.

In the production is taken into account the following structure of the production: energetic pellets $\mathrm{A}(30 \%)$, energetic pellets B $(35 \%)$, litter pellets $(5 \%)$, granulated malt fodder GMF $(30 \%)$. The structure of the production concludes from the information provided by the company doing business on the market in the area but does not wish to be named, and respects the needs of potential customers and availability of the input materials. The difference of the individual products is in the input biomass content and consequent technical parameters of the output pellets. Composition of the input materials does not have any influence on the pelletisation process itself. Pellets are comprised of wheat straw, rape and corn powder, sunflower waste and husks and grain waste. B pellets are from peas and rape, barley, rape, sunflower, wheat and corn waste. Fodder is from malt and powder, chaff and rape powder. Litter is from wheat straw. 


\section{Construction of the multiperiodical balance model and deterministic evaluation of the variant solutions of the} investment projects

The most important parts of the model construction lie in the variables definition (decisive, exogenous, strategic, limiting, etc.) and estimate of the production and costs of the project. The model itself comprises of:

- Costs estimate: capital (pelletisation line, building, transformer), variable (costs of electrical energy, biomass, wage costs and costs of social and health insurance for employees), fixed

- Production estimate

- Depreciations

- Financing of investment (equity, loans), repayment scheduling

- Projected annual income statement

- Projected cash flow report

- Projected balance sheet

The presented multiperiodical balance model simulating a twelve-year-long period is created in the Excel table processor. The model solution accepts completely the input decisions of the decision-making subject and allows a simulation of various strategies in the field of production scale, investment financing conditions, in the loans as well as depreciation area. Due to the lack of space we include only the decisive report for the net present value quantification projected cash flow report of the B project (Table 1).

Table 1. Projected cash flow report of project B

\begin{tabular}{|c|c|c|c|c|c|c|}
\hline Year & $\mathbf{0}$ & 1 & 2 & 3 & 4 & 5 \\
\hline \multicolumn{7}{|c|}{ Cash inflow } \\
\hline Equity & 146264 & & & & & \\
\hline Loans & 585056 & & & & & \\
\hline Sales of pellets A & & 560334 & 560334 & 560334 & 560334 & 560334 \\
\hline Sales of pellets B & & 491400 & 491400 & 491400 & 491400 & 491400 \\
\hline Sales of litter & & 117618 & 117618 & 117618 & 117618 & 117618 \\
\hline Sales of fodder & & 769392 & 769392 & 769392 & 769392 & 769392 \\
\hline Total cash inflow & 731320 & 1938743 & 1938743 & 1938743 & 1938743 & 1938743 \\
\hline \multicolumn{7}{|c|}{ Cash outflow } \\
\hline Total capital costs & 731320 & & & & & \\
\hline Operations costs & & 1484088 & 1484088 & 1484088 & 1484088 & 1484088 \\
\hline Repayment of loans and interests & & 135133 & 135133 & 135133 & 135133 & 135133 \\
\hline Income tax & & 62336 & 63395 & 64507 & 65674 & 66900 \\
\hline Total cash outflow & 731320 & 1681558 & 1682617 & 1683729 & 1684896 & 1686121 \\
\hline Net cash flow & $\mathbf{0}$ & 257185 & 256126 & 255015 & 253847 & 252622 \\
\hline Cumulative cash flow & $\mathbf{0}$ & 257185 & 513312 & 768326 & 1022174 & 1274796 \\
\hline Capital costs covered by own assets & 146264 & & & & & \\
\hline Equity return & -146264 & 257185 & 256126 & 255015 & 253847 & 252622 \\
\hline Present value & & 244938 & 232314 & 220291 & 208841 & 197936 \\
\hline Discount rate & $5 \%$ & & & & & \\
\hline NPV & 2626722 & & & & & \\
\hline
\end{tabular}

Source: self-calculated

The efficiency of the investment project is assessed by using the method of the equity assessment techniques. The NPV to the equity is calculated in a way that from the net cash flow in the individual years is deducted the investor's own investment and consequently is the cash flow discounts to the present value. Based on the calculated NPV value of the B project can be stated that the investment project scenario is acceptable whereas the NPV is positive and reaches the amount of $2626722 €$. The A project reaches much lower value of NPV in the amount of $377514 €$. We can summarise from the results that more profitable investment is the purchase of the B pelletisation line.

By combination of different use of the line, various working time (24-hour-long production or 12-hour-long production) and diverse financing mean were created the 4 following variants and 2 subvariants:

Variant 0: initial model, which works with $100 \%$ use of the line, financial sources in a ratio between equity and loans 20:80.

Variant 1: works with $80 \%$ line production and financing of the project in a ratio of 50:50.

Variant 2: line produces $90 \%$ of the possible volume and the project is financed from the own resources only.

Variant 3: production works at $70 \%$ and the entire investment is financed from the loan capital.

Variant 4: production at $85 \%$ and investment is financed in a ratio of 70:30.

All variants have 2 subvariants which differ in the working time:

Subvariant 1: 24-hour-long production- in 3 shifts,

Subvariant 2: 12-hour-long production- in 2 shifts.

The individual variants were considered with the same discount rate of $5 \%$. All variants were evaluated for the period of 12 years. 
Table 2. NPV of deterministic evaluation of variants

\begin{tabular}{lcc}
\hline & Line A & Line B \\
\hline Variant 0.1 & 377514.35 & 2626722.00 \\
\hline Variant 0.2 & 36985.64 & 807218.06 \\
\hline Variant 1.1 & 66112.33 & 1283048.10 \\
\hline Variant 1.2 & -135198.90 & 112093.30 \\
\hline Variant 2.1 & 218818.57 & 1941745.00 \\
\hline Variant 2.2 & -49106.58 & 456643.08 \\
\hline Variant 3.1 & -106071.35 & 624352.45 \\
\hline Variant 3.2 & -221290.65 & -270183.54 \\
\hline Variant 4.1 & 146536.91 & 1613407.22 \\
\hline Sariant 4.2 & -92152.45 & 295506.31 \\
\hline
\end{tabular}

Source: self-calculated

From the final NPV values can be summarised that with the both lines are more efficient the first original variants. On the basis of the results can be evaluated that a significant influence on the investment value has the working time. It is relevant mainly with the A line where the variants with 12-hour production are in the negative values of the NPV and so the investment intentions realised in this way would decrease the enterprise value. On the contrary the investment into the B pelletisation line seems to be very profitable which is in positive NPV value with both versions of the working time. The B line is in negative NPV value only with the variant of 12-hour production with considerably lowered performance of the line to $70 \%$. Changes in the financing forms of the individual investment intentions did not have any significant impact on the total NPV value.

\section{Construction of the simulation model of the investment project risk evaluation}

During the simulation model construction is necessary to identify the risk factors via the sensitivity analysis and subsequently choose the suitable type of the probability distribution and determine the parameters of the selected criterions. From the project A sensitivity analysis results is clear that the most important risk factors (in the brackets is stated a change of the NPV caused by $10 \%$ change of the factor) should be fodder sale price (48\%), pellet A price $(35 \%)$, pellet B price $(31 \%)$, costs of biomass for fodder $(26 \%)$, costs of biomass for pellets A (20\%) and costs of biomass for litter $(13 \%)$. The other factors did not bear any significant impact on the change of the NPV. From the sensitivity analysis of the B project the following appears to be the risk factors: fodder price $(21 \%)$, pellet A price $(15 \%)$, pellet B price $(13 \%)$ and costs of biomass for fodder $(11 \%)$.

The factors which were defined as important by the sensitivity analysis are in the stochastic model formulated as random variables with a certain probability distributions. To estimate these distributions were used subjective estimates based on experts' statements, completed with price analysis from the previous years. On the grounds of these discovered facts were the risk factors described by the triangular distribution where the parameters of the distribution represent pessimistic, optimistic and the most probable estimate of the risk factors.

The simulation itself was realised via the @Risk for Excel programme based on the Monte Carlo method. The results of the simulation analysis are primary statistic indicators NPV, distribution function and critical values of the target indicator.

The efficiency of the investment intentions can be evaluated on the basis of the critical values of the target indicators (Table 3). The investor is willing to bear only a certain risk while investing. Under the condition that the decision-making subject is risk averse, we suppose that investor is willing to accept a 10 up to $35 \%$ risk.

The percentage values set probabilities where the NPV drop under the value assigned to the given probability. Tables 3 and 4 depict the critical values of NPV for the project A and B variants.

Table 3. Critical values of NPV for the individual variants of the A project

\begin{tabular}{lrrrrrr}
\hline & $\mathbf{1 0 \%}$ & $\mathbf{1 5 \%}$ & $\mathbf{2 0 \%}$ & $\mathbf{2 5 \%}$ & $\mathbf{3 0 \%}$ & $\mathbf{3 5 \%}$ \\
\hline Variant 0.1 & 229921 & 259746 & 283723 & 303434 & 322281 & 338361 \\
\hline Variant 0.2 & -47049 & -29308 & -16272 & -6381 & 3269 & 13032 \\
\hline Variant 1.1 & -77614 & -50923 & -26341 & -7364 & 5505 & 20906 \\
\hline Variant 1.2 & -204561 & -191210 & -182173 & -171680 & -162843 & -155703 \\
\hline Variant 2.1 & 81698 & 113291 & 132241 & 145984 & 162572 & 177162 \\
\hline Variant 2.2 & -127379 & -111098 & -99516 & -89320 & -81076 & -72221 \\
\hline Variant 3.1 & -225110 & -206228 & -191009 & -174748 & -158979 & -145997 \\
\hline Variant 3.2 & -278687 & -267474 & -260764 & -252812 & -245755 & -238784 \\
\hline Variant 4.1 & 1939 & 33221 & 53608 & 72702 & 85452 & 105177 \\
\hline Variant 4.2 & -168525 & -152060 & -142583 & -131823 & -123504 & -114876 \\
\hline Sour 525
\end{tabular}

Source: self-calculated 
Table 4. Critical values of NPV for the individual variants of the B project

\begin{tabular}{lrrrrrr}
\hline & $\mathbf{1 0 \%}$ & $\mathbf{1 5 \%}$ & $\mathbf{2 0 \%}$ & $\mathbf{2 5 \%}$ & $\mathbf{3 0 \%}$ & $\mathbf{3 5 \%}$ \\
\hline Variant 0.1 & 2259731 & 2325317 & 2370498 & 2415027 & 2448441 & 2494270 \\
\hline Variant 0.2 & 627741 & 656950 & 688434 & 713463 & 733666 & 756546 \\
\hline Variant 1.1 & 1000835 & 1053323 & 1105066 & 1139035 & 1182620 & 1212798 \\
\hline Variant 1.2 & -54402 & -25980 & -1097 & 21018 & 40741 & 60430 \\
\hline Variant 2.1 & 1612494 & 1671812 & 1718042 & 1762133 & 1799524 & 1831965 \\
\hline Variant 2.2 & 298699 & 328854 & 356871 & 377667 & 397118 & 411560 \\
\hline Variant 3.1 & 358307 & 417257 & 459083 & 497039 & 528807 & 556762 \\
\hline Variant 3.2 & -415226 & -386849 & -366519 & -348404 & -330994 & -316035 \\
\hline Variant 4.1 & 1295990 & 1358097 & 1405269 & 1452137 & 1490965 & 1522860 \\
\hline Variant 4.2 & 120182 & 150608 & 183009 & 207771 & 229058 & 246852 \\
\hline
\end{tabular}

Source: self-calculated

From the results stated in the table we can with $10 \%$ probability expect that the NPV value for the 0.1 variant of the project A is lower than $229921 €$. Similarly with $25 \%$ probability we might expect that NPV for this strategy will be less $303434 €$. When the decider's aversion to risk is taken into consideration, in case of negative values of the NPV is the investment project for the decision-making subject inefficient. Therefore all variants, except the $0.1,2.1$ and 4.1 , of the A project are inefficient for the investor. In the B project would be for the decision-making subject inefficient only variants 1.2 and 3.2 .

To evaluate the efficiency of the investment projects is possible as well via the distribution function and the density function. The distribution functions represent the basis for the complex comparative comparison of the individual strategies efficiency with a respect to the risk according to the stochastic dominance.

The Fig. 1 depicts the dominance of the $1^{\text {st }}$ degree of the 0.1 project A against all other variants of this project, it means that the 0.1 variant dominates all other variants of the project $\mathrm{A}$. The same situation can be observed with the project B where the 0.1 variant is dominant over the other variants (Fig. 2). In the project A can be seen the presence of the stochastic dominance of the $2^{\text {nd }}$ degree among the $0.2,1.1,1.2,2.2,3.1$ and 4.2 variants.

On the basis of the distribution functions and the rule of the stochastic dominance of the $1^{\text {st }}$ degree is the second most efficient variant of the project A the 2.1 variant which is dominated only by 0.1 variant.

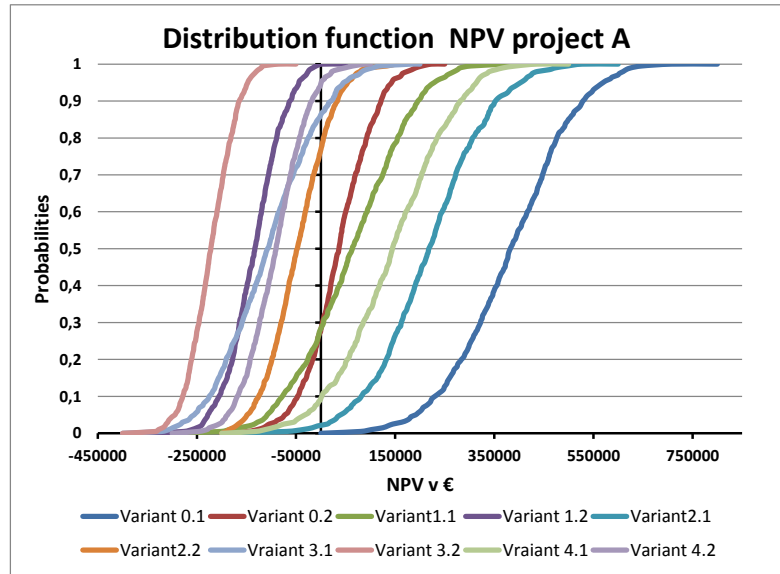

Figure 1. Distribution functions of NPV CF for the individual variants of the A project

Source: own work

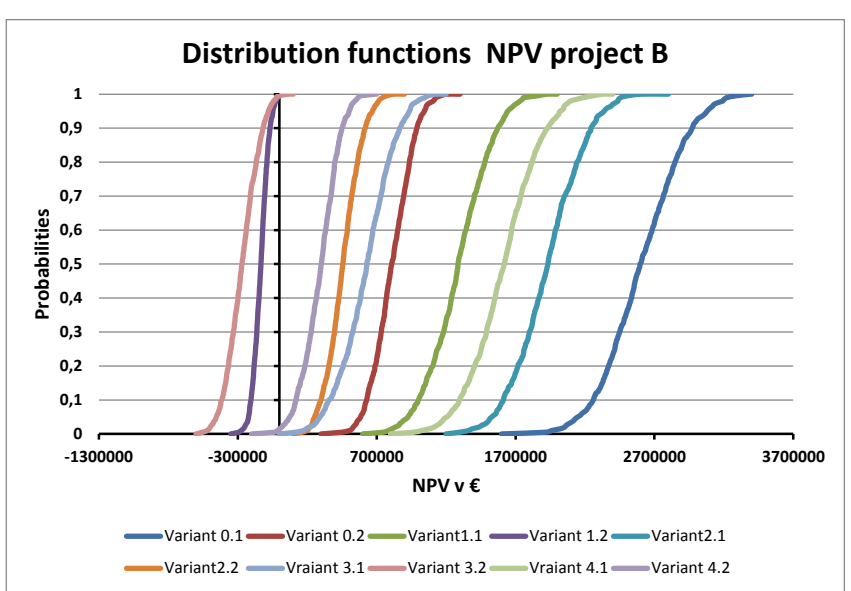

Figure 2. Distribution functions of NPV CF for the individual variants of the B project

Source: own work

The distribution functions of the project $\mathrm{B}$ depict the following structure of the dominance of the 5 most effective variants on the grounds of the stochastic dominance of the first grade: $0.1 \succ 2.1 \succ 4.1 \succ 1.1 \succ 0.2$. Based on the comparison of the distribution functions of the most efficient variants of the both project can be summarised that the variants of the project $\mathrm{B}$ dominate the variants of the project $\mathrm{A}$.

\section{CONCLUSIONS}

The aim of the paper was to create an investment project to purchase a pelletisation line to process the biomass in a form of agropellets. The investment project resulted from an offer of the line supplier while two pelletisation lines with different technical parameters and purchase costs were taken into consideration.

We chose a model approach to create the investment project due to the fact that it enables the business subject to react flexibly to the current changes. Via the multiperiodical balance model formed in the Excel table processor were deterministically assessed the variant solutions of the investment intention on the basis of the criterion - net present 
value (NPV). From the deterministic analysis resulted that both investment projects are profitable since the evaluation criteria of the NPV in both projects reached positive figures. In case of making a decision according to the net present value indicator is more profitable the B project with a higher average performance of the pelletisation line whose NPV (2 $626722 €$ ) is higher than the NPV value of the investment intention into the line A purchase (377 $514 €$ ).

The model solution accept fully the initial decisions made by the decision-making subject and allows a simulation of various strategies in the range of production, investment financing conditions - in the loan as well as depreciation area. In the paper are stated the results of the various variants of the individual projects concluding from the changes of line capacity use, working time, pelletisation line performance, in addition to the structures of the project financing.

In the next part of the paper is the investment project risk taken into consideration via the simulation model. The factors influencing a change of the selected criterion were identified by means of the sensitive analysis. With the A project were the risk factors: biomass costs for A, B pellets and fodder, and sale prices of products A, B pellets and fodder. With the B project we determined using the sensitivity analysis the risk factors of the A, B pellets prices and fodder as well as costs for the biomass as fodder. The risk factors defined in the mentioned way were formulated as random variables with a certain probability distribution in the simulation model. On the basis of the critical values of the target indicators the investor with a risk averse attitude willing to bear 10 to $35 \%$ risk can reject the variant solutions where the NPV drops to negative value. It is only up to the investor to define up to what level he is willing to take the risk related to the investment.

The outcome in a form of the distribution functions represents a core for the complex comparative comparison of efficiency of the individual strategies respecting the risk according to the rules of the stochastic dominance. The simulation procedures verified in this case the preferences of the individual variants which were gained on the basis of the deterministic evaluation of the efficiency of the investment projects.

Taking the risk into account can lead to the order of preferences of the individual projects, mostly when considering factually different projects whose NPV in the deterministic assessment is approximately the similar.

\section{REFERENCES}

1. Fáber, A. 2012. Atlas využívania obnovitel'ných zdrojov energie na Slovensku (The Atlas of the Usage of Energy from Renewable Resources in Slovakia), Bratislava: Energetické centrum, 2012. ISBN 978-80-969646-2-8. (In Slovakian)

2. Lumby, S. 1996. Investment Appraisal and Financial Decisions, London: Chapman \& Hall, 1996. ISBN 0-412-58840-4.

3. Northcott, D. 1992. Capital Investment Decision-Making, London: Academic press LTD, 1992. ISBN 0-12-521685-8.

4. Repiský, J. 2000. Tvorba a hodnotenie investičných zámerov pomocou modelovej techniky (The Creation and Evaluation of Investment Plans with Modelling Techniques), Monograph. Nitra: SPU, 105 p. (In Slovakian)

5. Repisky, J. 2006. The evaluation of investment strategies under risk. Management: Journal for Theory and Practice Management, Vol. 11, Iss. 44, pp.36-45.

6. Sojková, Z. 2000. Aplikácia analýzy rizika v investičnom rozhodovaní, (The Application of Risk Analysis in the Investment Decision Making Process). In: Sborník př́spevku z konference k aktuálním otázkam rozvoja české ekonomiky a univerzitního ekonomického vzdelávaní, MZLU Brno, 2000. pp. 147-152. ISBN 80-85615-87-8. (In Slovakian) 